\title{
FACEBOOK: UMA ANÁLISE SOBRE A ONDA DE MANIFESTAÇÕES E PROTESTOS EM JUNHO DE 2013 NO BRASIL
}

\author{
Nicolle C. Sotsek ${ }^{1}$ \\ Rangel Ramiro Ramos ${ }^{2}$
}

\begin{abstract}
Resumo
O objetivo deste artigo é estudar o papel do Facebook como instrumento comunicacional efetivo durante a onda de manifestações ocorrida em junho de $2013 \mathrm{em}$ diversas cidades brasileiras. A pesquisa foi organizada em duas etapa: na primeira, é apresentada a fundamentação teórica sobre o interesse humano pela interatividade e também a apreciação de conceitos relacionados a comunicação e recepção na cultura de massa e na cibercultura. Depois são apresentadas as impressões resultantes da análise realizada através da ferramenta quantitativa Survey, visando avaliar a repercussão sobre a onda de protestos no Brasil. O objetivo dos pesquisadores foi investigar o ciberativismo, procurando verificar se o Facebook pode ser considerado uma ferramenta que possibilita de maneira efetiva a participação política e ideológica dos seus usuários na esfera pública brasileira.
\end{abstract}

Palavras-chaves: Comunicação, participação política, esfera pública, ciberatismo.

\begin{abstract}
The aim of this article is to study the role of the Facebook as an effective communicational tool during the wave of protests that took place in June 2013 in several Brazilian cities. The research was organized in two steps: first, it is shown some theories about people's interest for interactivity, as well as the concepts about communication and reception in mass culture and cyberculture. Next, we present our impressions of an analysis produced with the use of a tool called "Survey", in which we tried to evaluate the repercussion of the wave of protests. Our purpose was to study cyberactivism, trying to verify if Facebook can be effective for its user in political and ideological participation in the Brazilian public sphere.
\end{abstract}

Keywords: Communication, political participation, public sphere, cyberactivism.

\section{Introdução}

Em sua edição de 18 de junho de 2013, o jornal O Estado de S. Paulo dedicou 11 páginas para falar sobre a onda de protestos do mês de junho de 2013, que mobilizou o Brasil. O jornal apontou que, pelas redes sociais, 79 milhões de internautas foram potencialmente impactados pelos compartilhamentos sobre os protestos no Brasil. Segundo o jornal, "o mapeamento foi realizado online pela empresa Scup. 'O monitoramento mostra que essas mensagens chegaram a todas essas pessoas', explicou o gestor de comunicação da empresa, Eliseu Barreira Junior" (p. A15).

\footnotetext{
${ }^{1}$ Mestranda em Engenharia de Produção pela Universidade Federal do Paraná. Professora na Faculdade Educacional de Araucária.

${ }^{2}$ Graduado em Teologia pela Faculdade Teológica Batista do Paraná, professor-tutor na Faculdade Teológica Batista do Paraná.
} 
Matéria de Mariana Congo, de 23 de janeiro de 2013, demonstra que o Brasil foi o país que mais agregou usuários ao Facebook no ano de 2012 - são 64,8 milhões de brasileiros na rede social, correspondendo a um terço da população nacional ${ }^{3}$.

Este trabalho se propõe a apontar a efetividade da rede social Facebook como mecanismo de discussões relevantes para o desenvolvimento da sociedade, levando em consideração a opinião de usuárias. Assim como, o rádio e a televisão proporcionaram diferentes possibilidades de discussões políticas e sociais, o advento da internet apresenta mais um meio de comunicação das massas populares: as redes sociais, mas desta vez, é a interatividade que está em evidência. A intenção deste trabalho é observar o ciberativismo através do Facebook na comunicação da população brasileira durante os protestos de junho de 2013.

\section{Da Grécia à interatividade do século XXI}

A interatividade é inerente ao sentimento de cidadania que está presente na humanidade desde as antigas civilizações. Na Grécia antiga os homens (livres, cidadãos) se reuniam em praças no centro da polis a fim de discutir questões sobre a vida, a sociedade e a política. Dessas reuniões feitas na ágora surgiu a Filosofia; em Roma, essas reuniões aconteciam em fóruns realizados pelos representantes democráticos da população. Mas na Antiguidade somente os homens "livres" realmente participavam das discussões e das decisões referentes à sociedade. Contudo, com o passar dos anos, mais pessoas começaram a se dedicar na promoção da democratização da sociedade, investindo tempo e energia na participação das discussões políticas e sociais.

Jürgen Habermas interpreta que os espaços de discussões na era moderna não estavam mais restritos aos políticos, mas também entre os comerciantes burgueses, e denominou-os de esfera pública. Habermas (1984, p.29) diz que “com a expansão do comércio, o cálculo comercial, precisava, de modo mais frequente e exato, de informações sobre eventos espacialmente distanciados". Nesse momento surgem os primeiros correios e a imprensa, ambos a serviço do comércio, institucionalizando um sistema permanente de comunicação. $\mathrm{O}$ autor (p.30 e 31) diz que a esfera pública nasce no século XIII, com o pré-capitalismo, sendo um sistema de troca de informações entre comerciantes e senhores feudais, contudo é no século XVI que recebe a conotação de esfera do poder público.

\footnotetext{
3 Disponível em 25/06/2013: <http://blogs.estadao.com.br/radar-tecnologico/2013/01/23/um-terco-dosbrasileiros-tem-facebook-pais-se-torna-o-2o-em-numero-de-usuarios/>
} 
Esses sistemas permanentes de informação são analisados por autores que fazem da linguagem e do discurso seus objetos de estudo. Hobbes (1974, p.44) afirma que "se o discurso for apenas mental, consistirá em pensamentos de que uma coisa será ou não, de que ela foi ou não foi, alternadamente". Para Hobbes, interromper alguém, deixando-o na suposição de algo, é opinião alternada em relação à investigação da verdade sobre o passado e o futuro, "e tal como o último apetite na deliberação se chama vontade, assim também a última opinião na busca da verdade sobre o passado e o futuro se chama juízo". Para Hobbes, nenhum discurso pode terminar no conhecimento absoluto, seja no passado ou no futuro, ou seja, a cognição está sempre em formação.

Mas, Siebeneichler (1989, p. 142) afirma que Habermas interpreta a conclusão de Hegel sobre o agir comunicativo revelando que "os elementos que Hegel constata nada mais são do que representações básicas que decorrem de condições de simetria e de expectativas de reciprocidade das ações comunicativas", ou seja, o agir comunicativo é resultado de suposições e insinuações comuns e recíprocas, destinadas para uma interpretação através da linguagem.

Gabriel Tarde, a partir da concepção da sociedade como fator social de imitação, entende que a comunicação pode ser unilateral e recíproca entre os indivíduos. Antunes (2008, p.27) analisando essa postura de Tarde afirma que "só a partir da comunicação regular de informações e opiniões em sociedade é possível a influência do meio social sobre o pensamento individual". Esta influência do meio social sobre o pensamento individual é denominado pelos teóricos da comunicação como opinião pública.

Entretanto, existem controvérsias entre os estudiosos da comunicação sobre o conceito de opinião pública. Habermas (1984, p.114) diz que Jean-Jacques Rousseau é o primeiro teórico a utilizar o termo em seu Discurso sobre Ciências e Artes, feito na Academia de Dijon. Rousseau critica os letrados de sua época afirmando que estão preocupados apenas em serem notados e, por isso, têm uma postura contrária à opinião pública, que é adepta aos dogmas cristãos $^{4}$.

Já Lima e Oliveira (2012, p.1) afirmam que "o desenvolvimento da internet e das novas tecnologias trouxe um novo alento para os movimentos sociais e para a participação política", ou seja, toda a sociedade está possibilitada a executar esse processo de informações que dá origem à opinião pública. Porém, não precisam mais de um lugar físico para a execução deste processo, já que com o desenvolvimento das redes sociais, o ambiente virtual também se tornou

\footnotetext{
${ }^{4}$ ROUSSEAU, Jean-Jacques. Discurso sobre as Ciências e as Artes. Ed. Abril, São Paulo: 1973.
} 
um lugar em que as pessoas conseguem interagir, discutindo sobre temas variados que estão relacionados à sociedade.

Enfim, considera-se que atualmente a opinião pública está em qualquer lugar e pode acontecer a qualquer momento, desde que apresente elementos básicos como o emissor, a problemática e o sujeito ou grupo receptor que decodifica a mensagem e redireciona de volta para o emissor ou para um terceiro, seja produzido destinado às massas ou não.

\section{Mass media e a cultura de massa}

O conceito de massa surgiu no século XIX como consequência da Revolução Industrial. Ferin (2002), Ortega y Gasset (1973), Antunes (2008) dizem que a massa é constituída de um grupo de pessoas provenientes de grupos culturais e sociais distintos, que não atribuem valores a si mesmos e estão completamente alienados, sendo influenciados pelo espetáculo midiático. Ou seja, massa é o grupo que não está preocupado em desenvolver um pensamento crítico em relação à realidade da sociedade.

O termo mass media foi popularizado nos Estados Unidos na primeira metade do século XX. Trata-se de um conjunto de meios que tem por objetivo apresentar conteúdo a um grande público, diverso e não identificável. Cloutier (1975) define que os mass media são sistemas organizados para produzir, difundir e recepcionar informações. Eles são regulados por empresas públicas ou privadas especialistas na comunicação em massa. Enfim, media é a ferramenta utilizada para influenciar e compor a cultura de massa.

Citando as teorias de Marshall McLuhan, Lima e Oliveira (2012, p. 8) definem que os meios de comunicação, em primeira instância, funcionaram como extensões do sistema nervoso e "com o grande processo da informática, essas extensões tornaram-se cada vez mais amplas, a ponto de formar uma cultura específica que resulta da relação do indivíduo com a máquina: a cibercultura".

Cibercultura é o termo resultante de uma leitura do desenvolvimento da comunicação na história que inicia na 1) Cultura oral; 2) a escrita; 3) a impressa; 4) cultura de massa; 5) a cultura das mídias; 6) Cibercultura ${ }^{5}$. Entretanto, as eras não se extinguem por causa do início de outra, mas se entrelaçam recebendo enfoques diferenciados. A cibercultura é a fase da comunicação mais latente hoje. Nosso objeto de estudo, o Facebook, se encontra dentro dessa fase, mas em determinados momentos também se apresenta como instrumento dos mass media.

\footnotetext{
${ }^{5}$ SANTAELLA, Lúcia. Linguagens líquidas na era da mobilidade. São Paulo: Paulus, 2007.
} 


\section{O Facebook}

Chamado originalmente de thefacebook, o Facebook foi criado em 2004 pelo ainda estudante da universidade de Harvard Mark Zuckerberg. Recuero (2009) afirma que no primeiro momento o objetivo era criar uma plataforma que gerasse a interação entre os alunos iniciantes e os alunos formandos, promovendo maior comunicação entre as faixas etárias de entrada e saída da instituição de ensino. Ela era apenas uma rede de contatos para alunos da própria universidade.

Aos poucos o acesso foi aberto para outras instituições de ensino crescendo entre as universidades americanas, através de convites feitos pelos alunos. Recuero diz que em pouco tempo o website se tornou o mais acessado entre as instituições. Em menos de um ano já contava com um milhão de usuários.

Atualmente o website se tornou mais do que uma ferramenta de relações pessoais/sociais; ele também é visto como um negócio. Crespo, Ruiz e Parra (2009) afirmam que o Facebook é mais do que um espaço social, é um produto cultural cujo consumo a nível macro foi convertido em moda.

Cáceres (2011) afirma que o Facebook é uma plataforma de arquitetura simples, de alta convergência digital e acessibilidade, que está em todo tempo mudando para se adaptar com a nova cultura contemporânea. Outra vantagem do website é que ele é um meio de comunicação gratuito, e isso faz com que ele se torne um meio econômico.

A pesquisa realizada por Crespo, Ruiz e Parra mostra que os jovens usuários consideram que o Facebook promove um vínculo maior com os amigos, pois todos estão conectados a uma mesma rede interativa. E ele ainda pode ser apontado como um meio para fazer novas amizades a partir do contato realizado pelo amigo do seu amigo.

Em contrapartida, a mesma pesquisa mostra algumas desvantagens que o Facebook traz para o usuário, por exemplo: alto índice de informações com caráter supostamente duvidoso, informações alheias para todos os usuários, reduzindo a intimidade e a privacidade, grande perda de tempo podendo tornar-se um vício ao internauta, exposição da vida privada, entre outras.

Mesmo apresentando inconveniências, o Facebook é considerado pela maioria dos usuários como uma ferramenta completa, tendo aplicações que devem ser melhoradas como qualquer rede social. Cáceres atesta que o usuário ao acessar o Facebook tem uma forma de interação basicamente lúdica de prazer, onde através dela vive em um mundo de passeio e gozo.

Nestes locais os internautas podem interagir expressando suas opiniões a respeito da economia, política e de todos os problemas relacionados com a mídia e a sociedade. E quando 
isso é lançado através da rede ela pode servir em muitos casos como, influência positiva ou negativa a outros membros do website.

Portanto, seguindo esta linha de raciocínio, tudo o que é transmitido através de um pequeno clique pode apresentar uma repercussão gigantesca na rede social. As manifestações ocorridas no Brasil durante junho de 2013 exemplificam esse fenômeno. Os brasileiros mostraram que a mídia convencional apresentava uma "opinião pública” falaciosa em relação aos protestos, quando através do Facebook se posicionaram a favor das manifestações, enquanto, a princípio, os jornais impressos e os telejornais criticavam a postura dos manifestantes.

\section{Metodologia da pesquisa de campo}

No primeiro momento deste artigo foi apresentada a análise teórica sobre o tema em estudo para embasar a pesquisa em pauta. Agora, serão apresentados os resultados da pesquisa de campo que utilizou como metodologia científica um questionário online divulgado pelo próprio Facebook. O tipo de questionário escolhido é o classificado como descritivo, conforme Gil (2002), e tem como propósito verificar se a percepção dos fatos está ou não de acordo com a realidade.

Para enriquecimento da pesquisa, também será apresentado no apêndice algumas das respostas abertas que os internautas descreveram ao longo do estudo Survey. Esse tipo de abordagem é classificado por Bardin (2009) como sendo classificatório e segundo ele mesmo, essa forma de análise traz indagações necessárias para o entendimento.

O método de pesquisa está resumido na tabela 01, que foi desenvolvida exclusivamente para os internautas com idade acima de 15 anos, considerando-se que o universo probabilístico investigado está composto na maioria de internautas residentes na região Sul do Brasil.

TABELA 01- Ficha técnica do estudo.

\begin{tabular}{|l|l|}
\hline Universo Probabilístico & Usuários do Facebook de todo o Brasil \\
\hline Tamanho da Amostra & 264 internautas \\
\hline Técnica de Obtenção das informaçõe & Online : via Facebook \\
\hline Período da Pesquisa de Campo & 23/07 a 07/08 de 2013 \\
\hline Software utilizado & Google Doc \\
\hline
\end{tabular}

Fonte: Os autores

O questionário foi organizado em três partes: Perfil do usuário, Conhecimento Geral do facebook e o Facebook como ferramenta de comunicação, conforme quadro 02. 
QUADRO 02- VARIÁVEIS BÁSICAS DO QUESTIONÁRIO

\begin{tabular}{|c|c|c|c|}
\hline Variaveis & Detalhamento & objetivo & Análise \\
\hline \multirow{4}{*}{ Perfil do Usuário } & Sexo & \multirow{4}{*}{ Estabelece o perfil dos respondentes } & \multirow{4}{*}{$\begin{array}{l}\text { Informações diretas para validação } \\
\text { das respostas }\end{array}$} \\
\hline & Faixa etária & & \\
\hline & Escolaridade & & \\
\hline & Região de moradia & & \\
\hline $\begin{array}{l}\text { Conhecimento } \\
\text { Geral do Facebook }\end{array}$ & Utilização e finalidade & $\begin{array}{l}\text { Conhecer as razões para o uso } \\
\text { do facebook dos respondentes }\end{array}$ & $\begin{array}{l}\text { Relacionar as finalidades do uso } \\
\text { com o perfil do usuário }\end{array}$ \\
\hline \multirow{3}{*}{$\begin{array}{l}\text { Facebook como } \\
\text { ferramenta de } \\
\text { comunicação }\end{array}$} & Envolvimento com os protestos & \multirow{3}{*}{$\begin{array}{l}\text { Verificar se os respondentes } \\
\text { utilizaram o Facebook para se } \\
\text { manifestar durante as ondas de } \\
\text { protesto em junho de } 2013 \text { no Brasil }\end{array}$} & \multirow{3}{*}{$\begin{array}{l}\text { Relacionar os manifestantes } \\
\text { com os usuários do facebook }\end{array}$} \\
\hline & Pariticipação das manifestações & & \\
\hline & $\begin{array}{l}\text { Contribuição para propagação das } \\
\text { ideias de manifestação }\end{array}$ & & \\
\hline
\end{tabular}

FONTE: VAZ (2012) adaptado pelos autores

Os resultados apresentados a seguir são o cruzamento das perguntas respondidas pelos internautas. Optou-se por demostrar os dados desta forma para se ampliar a visão e a discussão a respeito do tema em estudo.

\section{Resultados}

\section{Relações jovens x Facebook x manifestações}

O questionário foi respondido por um grupo de 246 internautas. Cerca de $53 \%$ correspondem ao perfil masculino e $47 \%$ ao grupo feminino, sendo que no rank de idade $73 \%$ das mulheres apresentam idade entre 15-30 anos e no perfil dos homens tem-se 52\% com essa mesma relação de idade.

Efetuando-se o teste estatístico de Normalidade, com nível de significância de 1\%, relacionando as variáveis: gênero (masculino e feminino) com perfil jovem da amostra, concluise que as variáveis são dependentes, ou seja, há diferença significativa entre a amostra masculina e jovem em relação à amostra de feminina e jovem, como mostra a tabela 03.

\begin{tabular}{|l|l|l|l|}
\hline & Masculino & Feminino & Total \\
\hline Jovens & 73 & 90 & 163 \\
\hline Não Jovens & 68 & 33 & 101 \\
\hline Total & 141 & 123 & 264 \\
\hline
\end{tabular}

Tabela 03- Gênero X Perfil Jovem

A tabela 03 mostra que a maioria dos internautas que responderam o questionário são jovens entre 15 a 30 anos e que desta amostra (jovens-sexo feminino e masculino) $71 \%$ deles concordam que o Facebook foi o maior responsável pelo aumento da participação da população brasileira nas manifestações que ocorreram em junho de 2013. Cerca de 79\% dos internautas, 
considerados jovens na pesquisa, afirmaram que contribuíram com protestos utilizando o Facebook, seja por meio de um compartilhar ou por meio de um simples "curtir".

Ao serem questionados quanto à eficiência de protestar usando essa plataforma como instrumento, 94\% dos entrevistados afirma que o Facebook se comporta como uma ferramenta de oportunidade para que a reivindicação possa ser atendida. E, 35\% afirmaram que usam o Facebook como forma de protestar, expressar suas crenças e reivindicações como consumidores.

Além de se comportar como uma ferramenta de protesto e de contribuir para a organização das manifestações de julho de 2013 como afirma a grande maioria dos jovens entrevistados, o Facebook também é a principal ferramenta de comunicação entre eles. Quando questionados a respeito da forma que souberam dos protestos no Brasil $58 \%$ disseram que foi a partir da rede social.

\section{Relação Escolaridade Superior X Facebook X Manifestações}

Dos entrevistados cerca de 19\% apresenta nível escolar superior com especialização ou pós-graduação e deste grupo 68\% acreditam que o Facebook foi o maior responsável pelo aumento da participação nos protestos de junho de 2013. $43 \%$ deles afirmaram que utilizam o Facebook como instrumento de protesto ou apenas para manifestar suas opiniões e insatisfações como consumidores. Deste grupo, 60\% incentivam as reivindicações pelo Facebook através do modo "compartilhar" ou do modo "curtir" a postagem efetuada no website, pois acreditam que a plataforma é um instrumento real de manifestação.

Ao analisar a forma como esse grupo obteve conhecimento das manifestações, o Facebook ficou no segundo lugar como sendo o meio de comunicação mais utilizado por essa classe. Como mostra o gráfico 02.

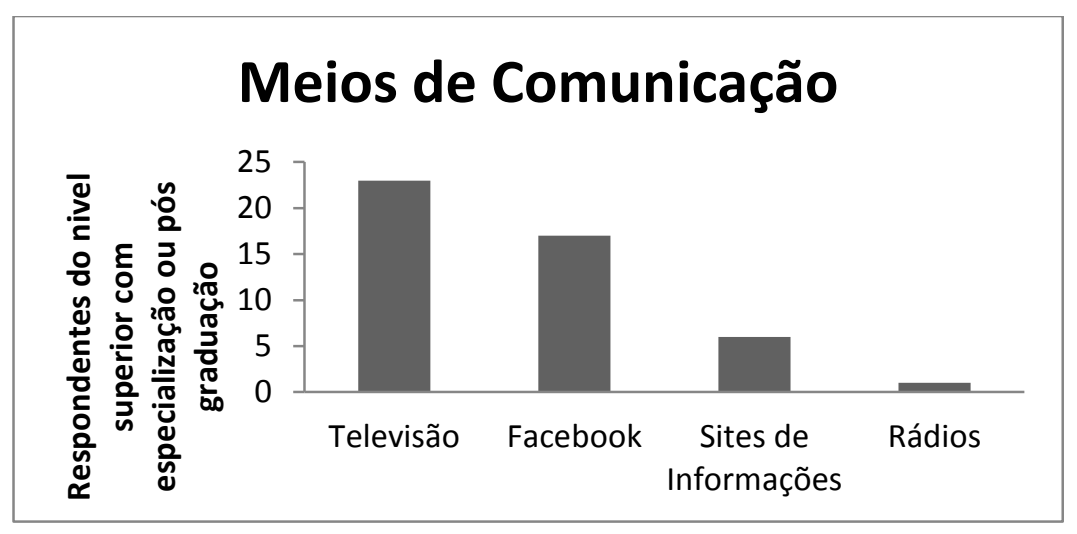

Gráfico 02- Meios de Comunicação 
O gráfico 2 aponta que para o perfil de usuário analisado, a plataforma Facebook é uma das ferramentas de comunicação mais importantes que o país tem atualmente. Na amostra total da pesquisa o Facebook apresentou o primeiro lugar como sendo o meio de comunicação mais utilizado pelos internautas.

\section{Relação Finalidade do uso X Facebook X Manifestações}

Dos internautas que responderam a pergunta a respeito da finalidade com que utilizam o Facebook cerca de 70\% afirmou que a principal utilização é o entretenimento, ou seja, é um meio de descontração e relaxamento. Como mostra o gráfico 03.

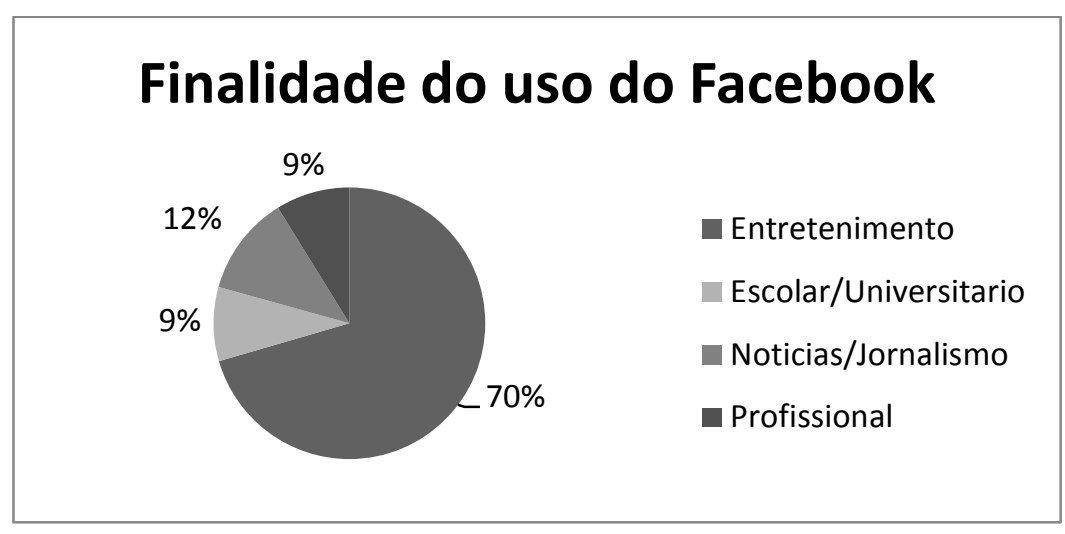

Gráfico 03- Finalidade do uso do Facebook

O interessante é que os internautas que usam o website como entretenimento quando questionados se expõem suas ideias políticas, suas crenças e insatisfações como consumidores cerca de $55 \%$ deles responderam positivamente. Ou seja, mesmo que usem esse meio para entretenimento aproveitam para se manifestarem de uma alguma maneira. E ainda 41,3\% deles acreditam que o Facebook é uma oportunidade de reivindicarem seus direitos e de se manifestarem.

Cerca de 96,1\% dos entrevistados acreditam que o manifesto ocorrido no Brasil em junho de 2013 apresentou tão repercussão pois o maior responsável pela aumento da participação do provo brasileiro foi o Facebook. Outro dado interessante é que 13 pessoas das que responderam ter participado de alguma comunidade que realizou os convites pedindo para o povo ir até as ruas se manifestarem, 11 delas fazem parte desta amostra (internautas que utilizam o facebook para entretenimento). E ainda dos 7 que responderam ter criado um convite para o manifesto, 5 dentre eles pertence a esse grupo.

Portanto, mesmo o grupo de internautas que utiliza o website apenas para entretenimento, se manifesta e incentiva a manifestação através do Facebook. Isto demonstra 
que o website contribui para o aumento da participação política e de opinião pública, permitindo ao cidadão mais um espaço de esfera pública.

\section{Considerações Finais}

O resultado do questionário apresentado demostrou que, para o grupo pesquisado, o Facebook é um meio gratuito de reivindicar seus diretos e permite aos usuários expressarem suas opiniões a respeito dos mais diversos temas.

A possibilidade de interação entre o ser humano, a máquina e a sociedade faz com que as redes sociais ganhem cada vez mais espaço e relevância no cotidiano, pois a cibercultura consegue potencializar a discussão que outrora estava localizada num espaço físico.

Vale considerar que a rede social proporciona indiretamente aos usuários se expressarem constantemente, sejam postando uma frase em seu perfil ou criando e compartilhando mensagens "polêmicas" que lidam com temas sobre a realidade da sociedade. E, por mais que a sensação de participação nos problemas da sociedade seja ilusória, ainda assim, a rede social em si tem seu valor, pois, de acordo com a pesquisa realizada, possibilitou ao grupo pesquisado expressar suas insatisfações, descontentamentos políticos e organizar-se para manifestações públicas durante o mês de junho de 2013.

Outro aspecto importante de ser abordado é que no ciberativismo as pessoas além de se expressarem com mais liberdade, também conseguem mascarar suas identidades com facilidade. Então, percebia-se nas manifestações a despreocupação dos manifestantes em separar a ciberatividade da atividade no espaço concreto. Por isso, a expressiva presença dos grupos de protestantes nas ruas usando máscaras para não serem reconhecidos.

Ao considerar que a opinião pública é elaborada a partir da expressão da sociedade, mesmo que influenciada pelas medias de massa, então, os levantamentos sobre a participação da sociedade no Facebook também poderiam ser considerados opinião Ppblica. Mas não há material científico suficiente neste trabalho para embasar uma conclusão definitiva sobre esse assunto. Contudo, baseando-se nos conceitos ideológicos de Habermas sobre gênese da esfera pública apresentados neste artigo, podemos dizer que as redes sociais são efetivamente consideradas mais um espaço para discussões políticas e ideológicas.

Sabe-se que essa discussão sobre o comportamento dos internautas e as possibilidades do ambiente virtual ainda é muito recente no Brasil, porém se nota que as redes sociais já são utilizadas para as massas expressarem suas opiniões, sejam essas consideradas opiniões públicas ou não. Por conseguinte, ariscar-se-ia propor a criação de uma rede social nacional com o cunho ideológico de promover as discussões políticas do Brasil. Um ambiente virtual em 
que as minorias pudessem se expressar com liberdade, mas providas de algum tipo de intermediação que transportasse a discussão em direção ao diálogo. Um canal de interatividade entre os políticos eleitos e seu eleitorado, abastecido de todos os recursos que uma rede social dispõe.

Contudo, a proposta deste artigo foi investigar se o Facebook pôde ser visto pelos usuários como uma possibilidade de esfera pública durante as manifestações de junho de 2013, a ponto de reivindicar de maneira efetiva as ações políticas e sociais brasileiras. Apoiando-se nos índices da pesquisa de campo entendeu-se que sim, o Facebook pode ser utilizado como esfera pública, entretanto a efetivação política das reivindicações ainda não é possível mensurar. (Artigo enviado em 12/10/2013, aprovado em 10/12/2013)

\section{Referências}

ANTUNES, Marco Antonio. Comunicação, Público e Multidão em Gabriel Tarde. BOCC, 2008. Disponível em: <http://www.bocc.ubi.pt/pag/antunes-marco-antoniocomunicacao-publico-multidao.pdf>. Acesso em: 19.08.2013.

BALLE, F. Dicionário dos Media. Lisboa: Didática Editora. Org., 2004.

BARDIN, L. Análise de Conteúdo. Lisboa, Portugal; Edições 70, LDA, 2009.

CAMPOS, Blas, B. CABERO, Julio, (2002) Familia y Medios de Comunicación.

Disponível em: 〈http://tecnologiaedu.us.es/revistaslibros/FAMILIA.htm>

Acesso em: 5/6/2008

COSTA, Nayara M da Silva. O Facebook como Ferramenta de Comunicação da Marca Origens. Universidade Vila Velha. Vila Velha, 2009.

CLOUTIER, Jean. A Era de EMEREC. Lisboa: Ministério da Educação e Investigação Científica - Instituto de tecnologia Educativa, 1975.

FERIN, Isabel. Comunicação e Culturas do Quotidiano. Lisboa: Edições Quimera, 2002. GONNET, Jacques. Educação para os Media - As controvérsias fecundas. Porto: Porto Editora, 2007.

GONNET, Jacques. Educação e mídias. São Paulo: Loyola, 2004.

HABERMAS, Jürgen. Mudança Estrutural da Esfera Pública. Rio de Janeiro: Ed. Tempo Brasileiro, 1984.

HOBBES, Thomas. Leviatã ou matéria, forma e poder de um estado eclesiástico e civil. São Paulo: Ed. Abril, 1974.

LIMA, Marcelo F. e OLIVEIRA, Eliane B. Cibercultura e cidadania cultural: considerações teóricas. Temática, 2012. 
LITTO, F. M; FORMIGA, M. Educação a Distância: um estado da arte, volume 2. São Paulo: Pearson Education do Brasil, 2012.

ORTEGA Y GASSET, José. A chegada das massas. In: ROSENBERG, Bernard e WHITE, David Monning. Cultura de Massa. São Paulo: Cultrix, 1973.

O Estado de São Paulo, Ano 134. N 43708. Edição de 21h30. Terça feira, 18 de junho de 2013.

RECUERO, Raquel. Redes Socias na Internet. Porto Alegre: Sulina, 2009

ROUSSEAU, Jean-Jacques. Discurso sobre Ciências e Artes. São Paulo: Ed. Abril, 1973.

SANTAELLA, Lúcia. Linguagens líquidas na era da mobilidade. São Paulo: Paulus, 2007.

SIEBENEICHLER, Flavio Bueno. Jürgen Habermas: razão comunicativa $e$ emancipação. Rio de Janeiro: Ed. Tempo Brasileiro, 1989.

\section{APÊNDICE}

\section{Pergunta descritiva}

Você acha que o facebook pode ser considerado um instrumento do povo brasileiro para manifestação ideológica ou política? Em sua opinião o brasileiro tem se utilizado desta ferramenta da maneira mais coerente? Por favor, justifique sua resposta.

Algumas das respostas:

“Ao meu ver os brasileiros usaram o facebook como uma ferramenta de comunicação em massa, para expor suas ideias e tentar junto ao povo mudar uma realidade política que já causa muita desordem no governo a anos."

“Com toda certeza, o facebook é um mega fone da população. Certamente através dele, nos tornamos unidos por compartilharmos muitas vezes uma mesma opinião e forte por lutar por ela, no entanto, tornar-se coerente é uma questão de maturidade e consciência ou seja, não é através da frequência que compartilhamos o face que construímos esses valores."

"Penso que quando usado de forma responsável é uma meio de comunicação que atinge muitas pessoas. Acho $q$ deve ser sim ser utilizado para protestarmos e emitirmos nossas opiniões, mas claro tudo isso de forma responsável."

"Sim, as notícias são publicadas como são de fato."

“Sim, pode ser considerado. Muitas pessoas o utilizam para expressar sua opinião politica."

"Sim, pois a mídia televisão e radio e outras são manipuladas e a rede social é livre para expor nossas ideias e ideais." 
"Eu acredito que sim, o facebook tem sido como dizem por aí : "a voz do povo". Não sei se a maioria está usando de forma mais coerente, mas uma minoria com certeza viu no facebook uma oportunidade de chamar, unir, mobilizar o povo por uma causa maior do que simplesmente o entretenimento virtual. Acredito que essa e talvez outras redes sociais como twitter e até o instagram tiveram uma parte bem importante na mobilização do povo. Até por dar a oportunidade que a TV não dá, de opinião sem edição, tanto por parte do povo quanto por parte dos famosos que também se mobilizaram, algo que talvez não fariam se a única opção fosse a TV."

"Já está comprovado que a mobilização para causas como manifestações pelos direitos e por melhorias, ou ainda para abaixo-assinados (como os do Avaaz, que têm uma grande visibilidade), ganham força quando estão no Facebook. Seria muito mais difícil atingir o mesmo número de pessoas sem uma ferramenta como essa, visto que, talvez, a mídia poderia ser um empecilho, como foi visto no começo dos protestos do mês passado. Acredito que estamos começando a perceber o poder das redes sociais."

"Sim, eu acredito que o facebook, por ser uma ferramenta livre, onde o sujeito escreve o que quiser, pode ser considerado um instrumento de manifestação ideológica elou política. Pelo mesmo motivo, entretanto, acredito que também é um centro de "desinformação", já que parte do que se lê lá não corresponde com a realidade. Sendo assim, acho que antes de mais nada, falta maturidade para a população lidar com a liberdade proporcionada pelo facebook, não opinando com falsa autoridade a respeito de temas que não dominam de forma alguma."

"O Facebook é uma das maiores ferramentas de manifestação usadas hoje. E sim, os brasileiros sabendo aproveitar essa poderosa ferramenta, faz várias ideias politicas e novas ideologias saírem do papel. A grande vantagem é o fato de milhares de pessoas terem acesso a informação, sem ser preciso um grande empenho dos usuários, tudo rápido e em tempo real."

"Sim, o facebook é um grande site nos dias de hoje, usado no mundo todo. Você expondo suas ideologias, e até a sua revolta, consequentemente muitas pessoas vão ver e muitas pessoas podem curtir, com isso vai divulgando até muitas vezes em outros países. O Facebook é uma grande ferramenta nas nossas mãos, agora é só sabermos usar!!"

"O facebook é um instrumento que o povo brasileiro utiliza pra se manifestar, no entanto não é de forma coerente, uma vez que muitas dos "ativistas" que ali estava durante as manifestações, não estavam tão ligados a causa e sim à como isso ia repercutir entre seus "amigos" e o que eles pensariam ou deixariam de pensar sobre tal pessoa."

"Creio que as redes sociais como um todo, em especial o facebook, tem contribuido muito para a abertura de espaço para discussões de cunho político. Talvez, por ser um meio de expressão relativamente recente, ainda não se tenha muita responsabilidade e maturidade no compartilhamento de algumas informações. $O$ furor da notícia nova é grande e divulgam-se informações sem a devida verificação de autenticidade. Ainda assim, acredito no poder transformador dessas novas mídias, e vejo com bons olhos a mobilização que o facebook é capaz de proporcionar..." 